\title{
Seasonal forecasts of the East African long rains: insight from atmospheric relaxation experiments
}

\author{
David MacLeod ${ }^{1}$ (D)
}

Received: 8 December 2018 / Accepted: 3 May 2019 / Published online: 11 June 2019

(C) The Author(s) 2019

\begin{abstract}
The impacts of recent droughts and floods over East Africa may have been avoided with accurate and timely early warnings. However skillful predictions for the long rains season from dynamical seasonal forecasts have long proved elusive and understanding of the drivers of interannual variability of this season is incomplete. Although recent work has highlighted several candidates for key drivers of variability during March-April, the representation of East African precipitation and links to remote processes in seasonal climate models is relatively unknown. This is investigated here through use of the atmospheric relaxation technique in coupled seasonal climate hindcast experiments, which also provide an estimate of the upper bound of seasonal predictability from remote sources. Results highlight the key role of the lower troposphere in the northwest Indian Ocean in controlling interannual variability, particularly in March and April. This is in support of recent work suggesting ascent-induced boundary-layer heating this region as a key driver of interannual variability. Results from single-variable relaxation experiments also reveal the importance of correct simulation of humidity for the proper representation of this link. Processes in the southwest Indian Ocean provide a control on May precipitation over southwest Kenya and northern Tanzania, highlighting the role of Somali jet variability in long rains cessation. Relaxation in more remote regions over the Pacific is unable to improve the representation of interannual variability over East Africa in general, although variability in the east Pacific appears to provide a weak control on March rainfall, consistent with previous hypotheses linking decaying ENSO events to early season rainfall. Finally, modelled precipitation anomalies are found to be insufficiently constrained to the coast of Africa. Relaxation (particularly in the northwest Indian Ocean) can improve these spatial biases, however the variance explained by these modes is systematically underestimated in the model and appears insensitive to remote processes. Inadequate representation of local processes over East Africa is proposed as the cause of this underestimation and several candidates are outlined.
\end{abstract}

Keywords East Africa $\cdot$ Seasonal prediction $\cdot$ Forecasting $\cdot$ Drought $\cdot$ Flood $\cdot$ Forecast-based action

\section{Introduction}

The 'long' rains (generally March to May) are a critical period in semi-arid East Africa, where a significant part of the population relies on rain-fed agriculture. Much of the region experiences a bi-modal rainfall climate, with most

Electronic supplementary material The online version of this article (https://doi.org/10.1007/s00382-019-04800-6) contains supplementary material, which is available to authorized users.

David MacLeod

macleod@ox.ac.uk

1 Atmospheric, Oceanic and Planetary Physics Clarendon Lab, University of Oxford, Parks Road, Oxford OX1 3PU, UK rain falling during the long rains and slightly less on average falling in the short rains (generally October to December). Although the long rains show less inter-annual variability than the short rains, there have still been significant extreme seasons in recent memory. Multi-season short and long rains failures in 2010/2011 and 2016/2017 led to crises which left over 12 million and 26 million people in need of food assistance in the region (OCHA 2011, 2018). Subsequently the 2018 long rains over Kenya were the wettest in 70 years and resulted in around 150 deaths and 300,000 displaced people (Govt. Kenya 2018).

Early warning of anomalous long rains rainfall is limited by no clear sources of seasonal predictability. Whilst decades of research has demonstrated high short rains predictability (arising from a strong teleconnection to El 
Niño Southern Oscillation and the Indian Ocean Dipole (ENSO, IOD) (Nicholson 2017), the long rains does not show a strong connection to remote global sea surface temperatures (SST) (Ogallo et al. 1988; Hastenrath et al. 1993; Mutai and Ward 2000). This lack of strong SST teleconnection is consistent with the low skill found for long rains precipitation in dynamical seasonal models at anything more than a zero-month lead time (Batté and Déqué 2011; Dutra et al. 2013; Mwangi et al. 2014; MacLeod 2018, 2019; Kilavi et al. 2018). For instance, the seasonal forecast issued ahead of the recent record-breaking 2018 wet season gave no signal that enhanced rainfall was imminent, less than one month before the start of the wet season (GHACOF 2018; Kilavi et al. 2018).

However despite the lack of clear predictable SST drivers, work on statistical forecasting suggests that the potential predictability of the long rains is higher than the current level of dynamical model skill. By using multiple linear regression models based on January precursor fields, a cross-validation correlation of 0.65 for long rains total rainfall has been found (Nicholson 2014), which is significantly higher than reported values at the same lead time from state-of-the-art dynamical models (Mwangi et al. 2014). Notably these statistical models generally find atmospheric fields to provide more predictability than SST, as it has been proposed that atmosphere-ocean feedbacks distort any link between SST and rainfall where coupled processes are important (Nicholson 2014).

Improved understanding of the drivers of interannual variability of the long rains can help to improve seasonal forecasts. To this end, Vellinga and Milton [hereafter VM18, (Vellinga and Milton 2018)] have carried out an extensive analysis of reanalysis and instrumental datasets over the region. This work showed three factors explaining 30-60\% of March-April precipitation variance: SST over the northwest Indian Ocean, the seasonal amplitude of the Madden-Julian oscillation (MJO) and the phase of the Quasi-Biennial Oscillation. Each factor interacts with East Africa rainfall by modifying the normal subsistence experienced over March and April. In order to improve seasonal forecasts for the long rains, it is important to understand the representation of precipitation over East Africa in dynamical models and the sensitivity of its interannual variability to non-local processes. Here this is investigated by applying the technique of atmospheric relaxation (Jung et al. 2010) to seasonal hindcasts of the long rains. As well as diagnosing the relative contributions of variability in remote regions to local seasonal rainfall, the technique also provides an estimate of the upper bound of predictability. The relaxation technique is described in more detail in the next section along with the experimental setup. This is then followed by presentation of results and finally a discussion.

\section{Experimental setup}

Experiments have been carried out using the ECMWF coupled atmosphere-ocean modelling system in seasonal prediction mode. The atmospheric model is IFS Cy41r1 run at T255 resolution (roughly $80 \mathrm{~km}$ near the equator) with 60 vertical levels, whilst the ocean model is NEMO at 1 degrees horizontal resolution with 42 vertical levels. Atmospheric initial conditions are based on the ERAInterim reanalysis (Dee et al. 2011) whilst ORA-S4 reanalysis is used for the ocean (Balmaseda et al. 2013). The control setup comprises a series of forecasts initialized every 1st February 1981-2014 and run for four months to reforecast each long rains season (here defined as March to May). For each start date a ten-member ensemble is run, with initial conditions for each member perturbed using singular vectors to account for initial condition uncertainty and physics tendencies perturbed at each timestep to account for model uncertainty (Leutbecher et al. 2017).

This control experiment provides a baseline from which to measure the impact of non-local atmospheric processes in a series of relaxation experiments, following the methodology introduced by Jung (Jung et al. 2010). In the relaxation method, certain model fields are nudged toward the ERA-Interim reanalysis field during the course of the integration, binding the atmosphere in a specified region to 'truth' whilst allowing the model outside the region to run freely. The relaxation is applied using a timescale parameter of $2 \mathrm{~h} 45 \mathrm{~min}$, following (Watson et al. 2016).

Experiments follow the control setup but with atmospheric relaxation switched on in certain regions. Details of the coordinates used to define these relaxation regions are given in Table 1 and presented on a map in Fig. 1. In order to reduce boundary effects a hyperbolic tangent smoothing is applied over 20 degrees at the edges of these regions (boundaries in Table 1 refer to the center of the 20。 smoothing). In certain experiments relaxation is applied only below or above a specified model level and in these cases the transition in the vertical is smoothed over eight model levels. N.B. the global experiment (GLOB) is not a true global relaxation which excludes East Africa; rather relaxation is not applied across the entire region 28-52E pole-to-pole.

The experiments have been designed in order to systematically identify regions where seasonal predictions for East Africa are sensitive to non-local processes. A globalrelaxation (GLOB) provides an upper bound on seasonal forecast skill from non-local sources, that is, the forecast skill which would be reached if the atmosphere outside of East Africa had zero error. Relaxation of tropical regions (INDI, WPAC, EPAC, ATLA) then measures the magnitude of the influence of the atmosphere overlaying each 
Table 1 Definition of the regions used for relaxation experiments

\begin{tabular}{lll}
\hline Experiment & ID & Relaxation box co-ordinates \\
\hline Control & CTRL & N/A \\
Global & GLOB & $90 \mathrm{~N}-90 \mathrm{~S}, 52 \mathrm{E}-28 \mathrm{E}$ (excluding East Africa) \\
Tropics & TROP & $20 \mathrm{~N}-20 \mathrm{~S}, 52 \mathrm{E}-28 \mathrm{E}$ \\
Indian Ocean & INDI & $20 \mathrm{~N}-20 \mathrm{~S}, 52 \mathrm{E}-110 \mathrm{E}$ \\
West Pacific & WPAC & $20 \mathrm{~N}-20 \mathrm{~S}, 110 \mathrm{E}-180 \mathrm{E}$ \\
East Pacific & EPAC & $20 \mathrm{~N}-20 \mathrm{~S}, 180 \mathrm{E}-290 \mathrm{E}$ \\
Atlantic & ATLA & $20 \mathrm{~N}-20 \mathrm{~S}, 290 \mathrm{E}-28 \mathrm{E}$ \\
Lower Tropics & LTRO & TROP, only relaxing levels below 700mb \\
High Tropics & HTRO & TROP, only relaxing levels above 200mb \\
Northwest Indian Ocean & NWIO & $20 \mathrm{~N}-5 \mathrm{~N}, 55 \mathrm{E}-80 \mathrm{E}$ \\
Southwest Indian Ocean & SWIO & $5 \mathrm{~S}-20 \mathrm{~S}, 55 \mathrm{E}-80 \mathrm{E}$ \\
\hline
\end{tabular}

The region used for NWIO follows that described in VM18 and SWIO is run as a control to test the sensitivity to this specific Northwestern Indian Ocean region
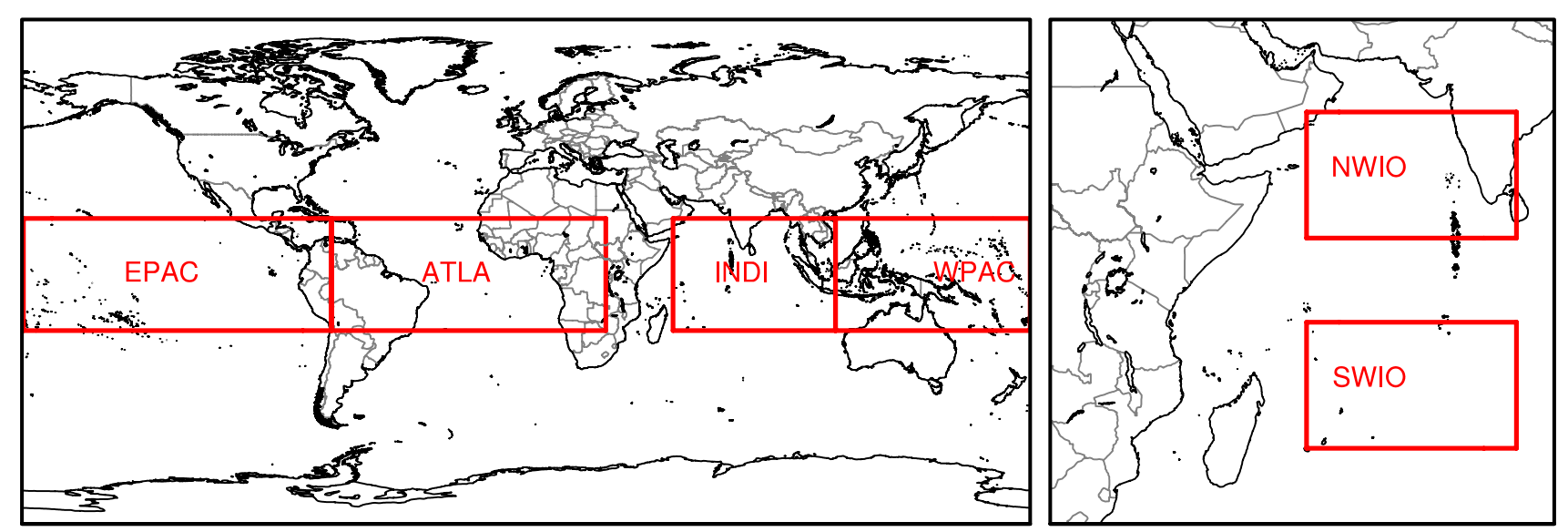

Fig. 1 Indication of regions used for relaxation experiments (full details in Table 1). Regions indicated in a are used to compare sensitivity to tropical regions. A larger all tropics region is also run (TROP), containing all four regions in $\mathbf{a}$, as well as a global region

tropical ocean basin. The influence of the lower or higher atmospheric processes is also examined by comparing a run with relaxation only below $700 \mathrm{mb}$ to a run where relaxation is active only above $200 \mathrm{mb}$ (LTRO and HTRO).

In addition, experiments are run to test one of the results of VM18 (Vellinga and Milton 2018). In this study, analysis of reanalysis and observational data identified a region in the northwest Indian Ocean as one of the key drivers of long rains interannual variability. Here, the same region is used in a relaxation experiment (NWIO). In an effort to test the result an experiment is run with a second region mirrored in the equator (SWIO). Given the equatorial position of East Africa, these NWIO and SWIO regions are roughly equidistant from the continent and a priori we might expect their impact to be roughly similar. If relaxation in the NWIO box shows a much larger impact than SWIO, this provides evidence in support of the VM18 hypothesis; that the where TROP is extended to the poles (GLOB). b Indicates regions used to test sensitivity to the Northwest Indian Ocean region described in (Vellinga and Milton 2018)

Northwest Indian Ocean shows a particular control on long rains interannual variability compared to elsewhere in the Indian Ocean (N.B. Hereafter when a compass direction is capitalised in the text it refers to a specific region defined in Table 1, otherwise it refers to a general direction).

For all experiments listed in Table 1, the fields relaxed are zonal and meridional wind components, temperature, surface pressure, atmospheric humidity and ozone. Table 2 contains details of additional experiments run with singlefield relaxation in order to further identify key processes in the NWIO experiment.

The CHIRPS precipitation merged gauge-satellite dataset is used (Funk et al. 2015) for verification, and analysis is carried out across the period 1981-2014. The accuracy of ERA-Interim precipitation is also assessed, whilst the GPCP precipitation observational dataset (Adler et al. 2003) is used as a reference to test the robustness of 
Table 2 Definition of the additional relaxation experiments used to evaluate the relative contribution of processes in the NWIO region

\begin{tabular}{ll}
\hline ID & Details \\
\hline NWIO & As NWIO (Table 1) \\
NLOW & As NWIO only relaxing levels below $700 \mathrm{mb}$ \\
NLDY & $\begin{array}{c}\text { As NLOW only relaxing dynamics (meridional and zonal } \\
\text { wind) }\end{array}$ \\
NLTE & As NLOW only relaxing temperature \\
NLSP & As NLOW only relaxing surface pressure \\
NLQX & $\begin{array}{c}\text { As NLOW only relaxing moisture fields (specific humidity, } \\
\text { liquid water and cloud fraction) }\end{array}$ \\
\hline
\end{tabular}

results to observational uncertainty and to evaluate the model simulation of precipitation anomalies over the ocean (since CHIRPS is a land-only dataset).

One important difference between the current work and the setup of others (Jung et al. 2010) is the use of a coupled model here. This essentially provides extra route for the relaxation to impact remote regions (i.e. through the ocean). Specifically, by using a dynamically coupled ocean model any atmospheric perturbation can modify surface exchanges of heat and momentum with the ocean within the relaxation region. This has potential to alter SST, which can spread beyond the immediate relaxation region and perturb the atmosphere outside of the immediate relaxation region.

Note that the assumption that any reanalysis data represents truth is also highly dependent on the quantity of the observational network assimilated into the data. In regions of sparse coverage (e.g. Africa) it is quite possible that reanalysis diverges significantly from 'truth'. Indeed, results shown later indicate the presence of large humidity biases in ERA-Interim over central Africa. However despite this, the use of reanalysis data as a relaxation target provides an estimate of the sensitivity of local precipitation to remote atmospheric processes.

\section{Results}

The impact of the relaxation experiments described in the previous section on East African long has been assessed. Analysis focuses on the mean state and spatial structure of precipitation anomalies, the seasonal prediction skill and representation of forecasts for a recent extreme event, as well as on experiments to diagnose errors in reanalysis humidity fields. Results are discussed both for the 3-month March-May (hereafter MAM) average as well as for individual months.

\subsection{Impact on mean bias and spatial structure of precipitation anomalies}

This first section considers mean precipitation biases and the spatial structure of precipitation anomalies. Figure 2 shows mean MAM precipitation biases for all experiments in Table 1. The mean rainfall from CHIRPS observations is shown in Fig. 2a, indicating rainfall maxima over Tanzania, Lake Victoria and Ethiopia. Over Kenya the maximum rainfall is located near the border with Tanzania and near the coast, whilst the semi-arid remainder of the country and most of Somalia receive around $50 \mathrm{~mm}$ across the season. The bias of the control run is shown in Fig. $2 b$. In general the model underestimates the rainfall by $10-30 \mathrm{~mm}$ with a larger dry bias over the maximum precipitation regions of Ethiopia and southern Tanzania and a wet bias over Lake Victoria. The experiments with the largest reduction in the bias are INDI and NWIO (Fig. 2e, k), whilst the experiments WPAC, EPAC, HTRO and SWIO (Fig. 2f, g, j, 1) show no impact on the bias beyond the control. This suggests that model processes in the Pacific, upper troposphere and Southwest Indian Ocean are not responsible for this dry bias, which is arising primarily in the northwest Indian Ocean.

It can be also seen that several relaxation regions (GLOB, TROP, ATLA, LTRO) introduce a large wet bias in the normally-dry regions of northern Ethiopia and Sudan. The common region to these experiments is the lower tropical troposphere in the ATLA region, indicating that this wet signal originates from the relaxation boundary there. Given the high transpiration over the Congo Basin it may be that this erroneous signal is related to some overestimation of the atmospheric moisture content in the ERA-Interim relaxation dataset. Indeed it has been found that the ERA-Interim dataset overestimates humidity over Africa in general (ECMWF 2019).

No relaxation experiments improve the wet bias over Lake Victoria, suggesting a local origin for this bias. Previous work with a coupled atmosphere-lake model over Lake Victoria (Song et al. 2004) have shown that wind-driven horizontal heat transport in the lake affects precipitation and concludes that inclusion of these coupled atmosphere-lake hydrodynamics in models leads to a reduction of precipitation compared to using a one-dimensional representation of the lake. From CY41R1, lakes have been included in the ECMWF system through the FLAKE subgrid parameterization (Balsamo et al. 2012), representing those at least $1 \%$ of the model gridbox (for these experiments this corresponds to a lake size of around $70 \mathrm{~km}^{2}$ ). This parameterization is based on a one-dimensional lake representation without a full structure and so it may therefore suffer from the same overestimation of precipitation and so is a candidate for the source of this bias. Similarly the dry bias over southern Tanzania encompasses a significant regional lake (Lake Malawi) 

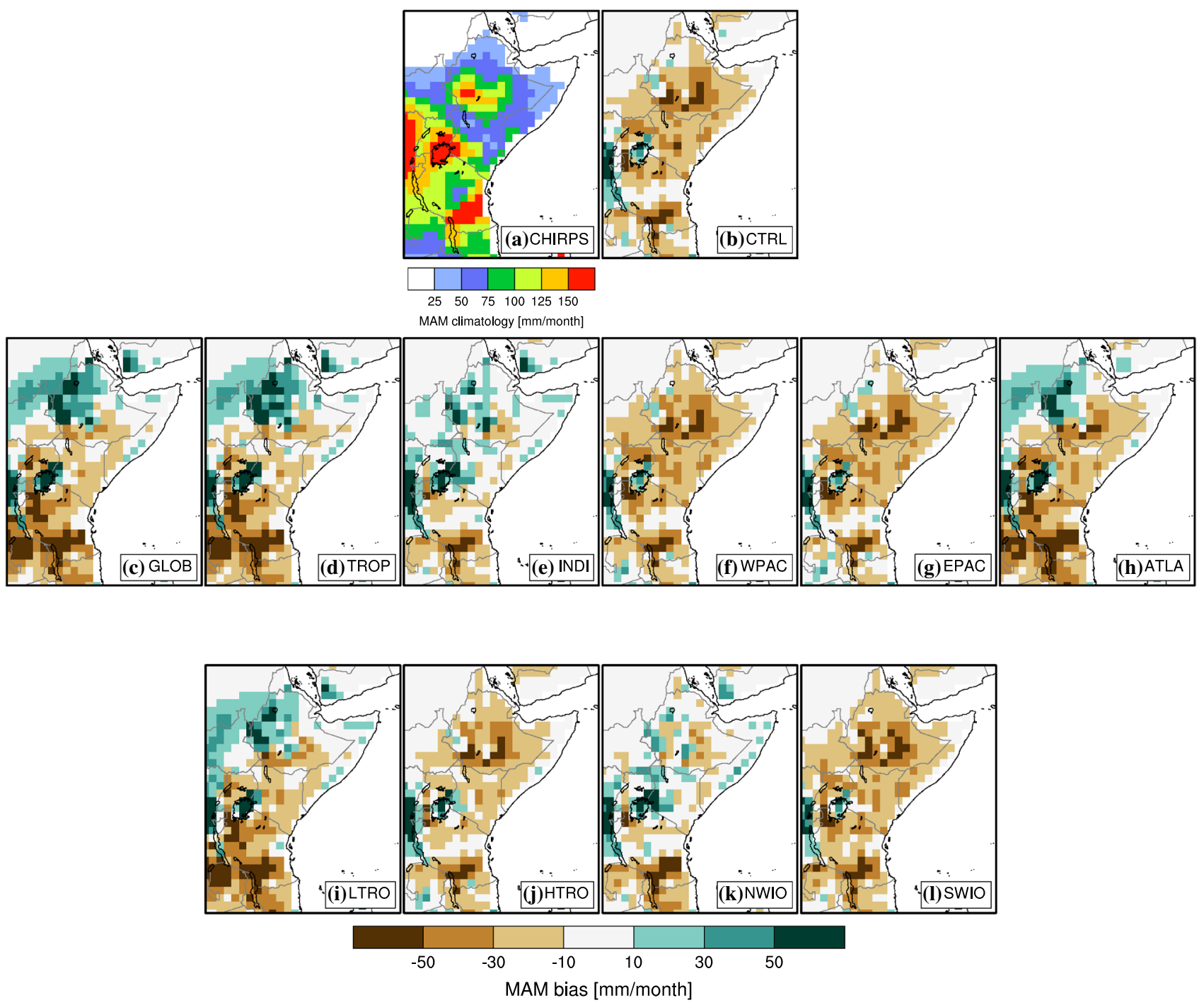

Fig. 2 Impact of experiments on total MAM precipitation. Observed precipitation for CHIRPS shown in a, bias with reference to CHIRPS shown for all experiments in $\mathbf{b}-\mathbf{l}$

and is unaffected by any relaxation experiments; this large dry bias here may also be related to lake processes.

The spatial structure of precipitation anomalies in model simulations is assessed in Fig. 3, shown as the first empirical orthogonal function (EOF) spatial pattern for each experiment. GPCP precipitation is used as a reference, as this includes precipitation values over the ocean and gives a complete picture of the structure of anomalies. Given that these EOF patterns are found to be quite different between the months, results for March, April and May are shown separately in Figs. 3, 4, 5. EOFs for the experiments are calculated across all years and members.

For March, the GPCP EOF over the region is a monopole aligned diagonally along with the coast of the Horn of Africa, extending west to Lake Victoria and south to Kenya. The central region of the pattern is relatively uniform, and falls off in power over the ocean. The total variance explained here is $29.6 \%$. In comparison, ERA-Interim variance explained is slightly lower (25\%), and the control variance explained is even lower (19\%). The structure in ERA-Interim shows broad similarity with GPCP although anomalies generally do not penetrate far enough into the continent and extend too far over the ocean.

For the control (Fig. 3c), the structure of March anomalies over land does not extend sufficiently up into the tip of the Horn of Africa and extend too far into the ocean. This 'bleeding' of the EOF pattern into the ocean is also reproduced in several experiments (WPAC, EPAC, HTRO and SWIO), with others (GLOB, TROP, INDI, NWIO) generally constraining anomalies to the coast in a more realistic way. The division of these experiments here reflects their observed impacts on the mean dry bias, suggesting 


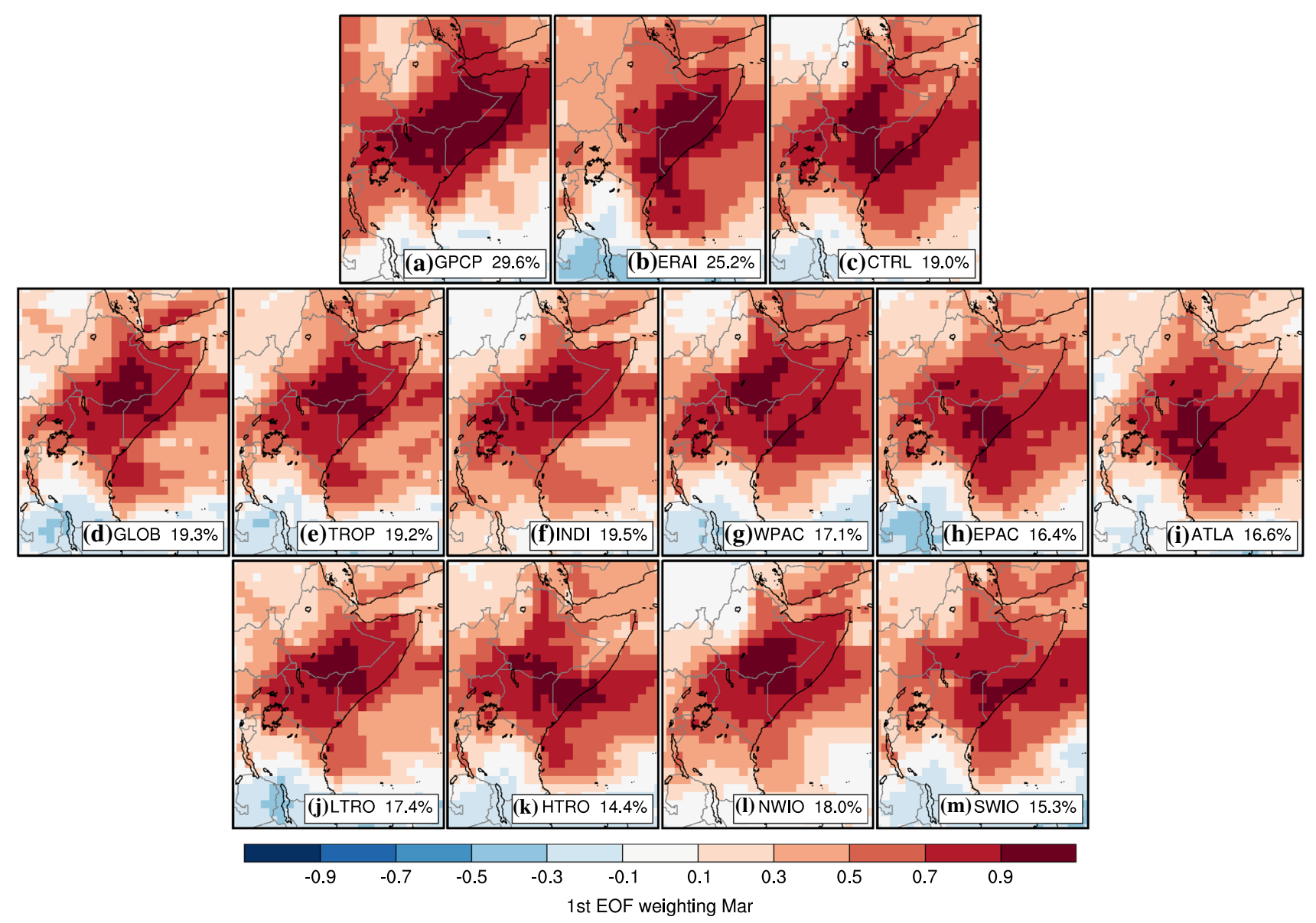

Fig. 3 Impact of experiments on the first EOF of March precipitation. a, b Show EOFs calculated from GPCP and ERA-Interim, whilst $\mathbf{c}-\mathbf{m}$ show this for the control and all experiments

that inadequate constraint of precipitation anomalies to the coast is a key factor producing the overall dry bias. However the variance explained is too low in the control (two-thirds of the GPCP value) and not improved with any relaxation experiment. This suggests the model is fundamentally unable to reproduce the power of this EOF, and/or local enhancement of variability is unrepresented in model processes. A boostrap-based estimate of the uncertainty in the estimate of the model variance gives a standard deviation ranging between 1-3\% across experiments and targets, suggesting the difference from observations is significant.

Results for April are shown in Fig. 4. The reference pattern is quite different to March, with the structure splitting into two poles; a smaller one over Lake Victoria and a larger one over the ocean. ERA-Interim is able to reproduce the pole over the ocean but not over Lake Victoria, whilst the control does not have sufficient power over the oceanic pole (Fig. 4b, c). Similarly to March the experiments including NWIO improve this spatial structure, implying that processes in this region are implicated in spatial structure errors. The variance explained by the first EOF in GPCP is slightly lower in April compared to March (24\%) and still underestimated in the control (18\%) with no relaxation experiment offering improvement. Indeed, NWIO has the largest underestimation, explaining only $13 \%$ of the variance by this first EOF.

Results for May are shown in Fig. 5. The structure of the pattern in GPCP is now located back tightly on land, over the tip of Somalia, whilst the model EOF patterns have large errors. ERA-Interim incorrectly has most power over the ocean, with one pole near to the GPCP pole and another off coast near the equator where the magnitude of the GPCP pattern is low (Fig. 5b). Interestingly the control has a large pole over the ocean and another near Lake Victoria which is quite similar to the GPCP pattern in April, suggesting the possibility of errors in simulating the correct timing of the seasonally-locked processes (Fig. 5c). Beyond the control, NWIO is able to center the pattern over Somalia and increase the variance by around 3\%, but still has an erroneous pole off the coast at the equator (Fig. 51).

The possibility of errors in the timing of the monthly processes motivates an examination of the inter-month 


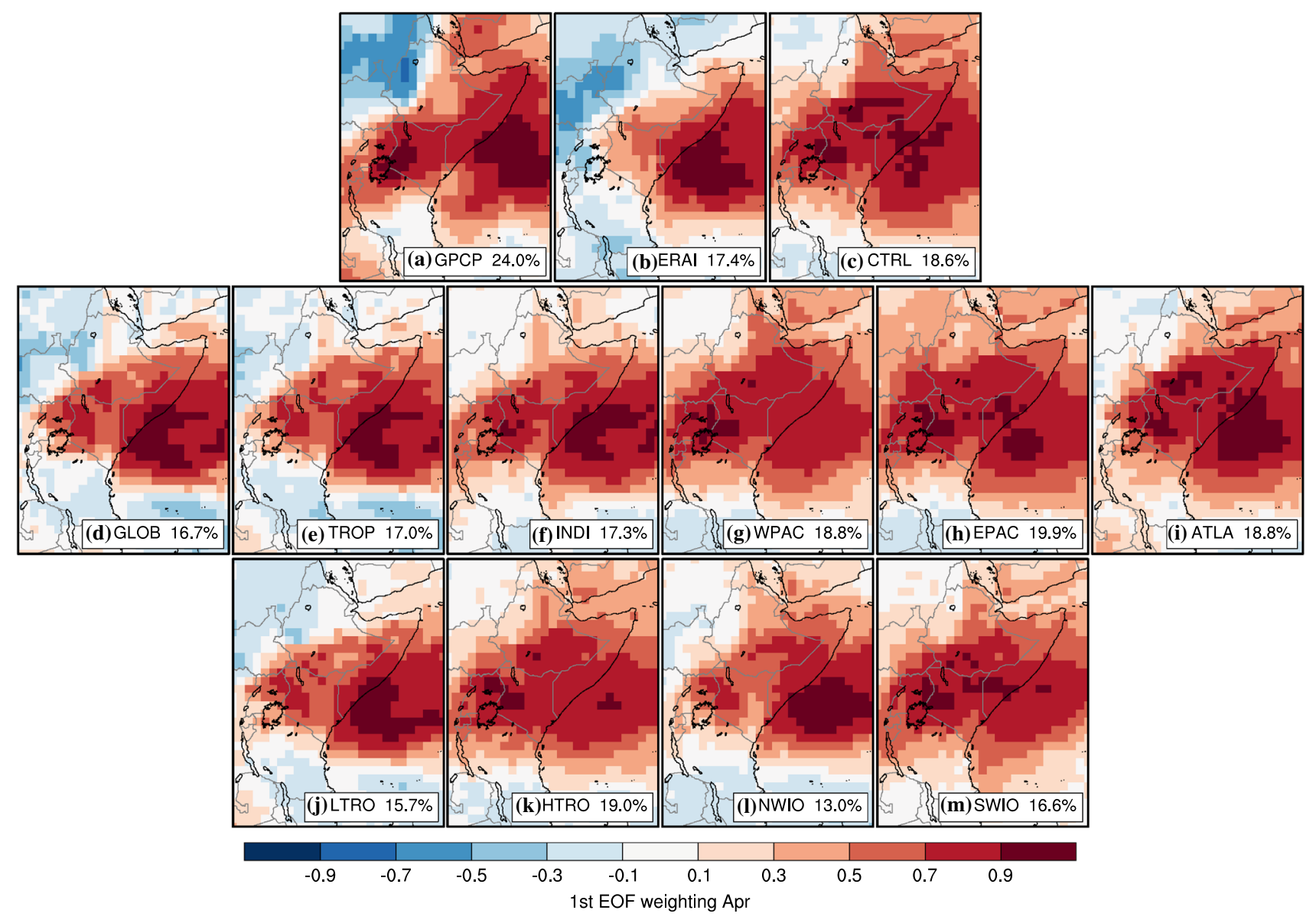

Fig. 4 Impact of experiments on the first EOF of April precipitation. a, b Show EOFs calculated from GPCP and ERA-Interim, whilst c-m show this for the control and all experiments

correlation and its representation in the model and experiments. This is shown by calculating the correlation between subsequent months across all years of observations (e.g. March precipitation correlated with April precipitation across 1981-2014). N.B. For the experiments, the average correlation calculated separately for each ensemble member separately is shown (as the ensemble mean correlation boosts the signal/noise ratio and so is not a fair comparison against a 'single-member' correlation calculated for observations). For brevity, results are shown in supplementary material and discussed below.

For the March and April, a significant positive relationship is seen over southern Somalia, Kenya and Ethiopia Somalia and this is not present in the model (supplementary Fig. 1). Rather, individual model members show low correlation between March and April across the whole region, with only some significant positive relationship apparent over the Indian Ocean. Between April and May the correlation is actually negative over Somalia and positive over Tanzania. Again, this is not captured within individual members (supplementary Fig. 2). These results suggests that the model is not perfectly representing the persistence of precipitation influences throughout the long rains. In general these month-month precipitation correlations are improved in the relaxation experiments, particularly so for the NWIO experiment.

\subsection{Impact of remote relaxation on forecast skill and predictions of the 2011 long rains drought}

We turn now to the impact of the relaxation experiments on forecast skill. Figure 6 shows the ensemble mean Pearson's product-moment correlation (hereafter refered to simply as correlation) of MAM precipitation against CHIRPS for all experiments. Results for individual months March, April and May are shown in Supplementary Figs. 3-5. The control (Fig. 6a) shows the expected low correlation over most of the region with most areas showing correlations below 0.4, consistent with previous work (Batté and Déqué 2011; Dutra et al. 2013; Mwangi et al. 2014; Kilavi et al. 2018). Parts of Kenya, northern Tanzania and Ethiopia show significant correlations, reaching up to 0.6 over Lake 


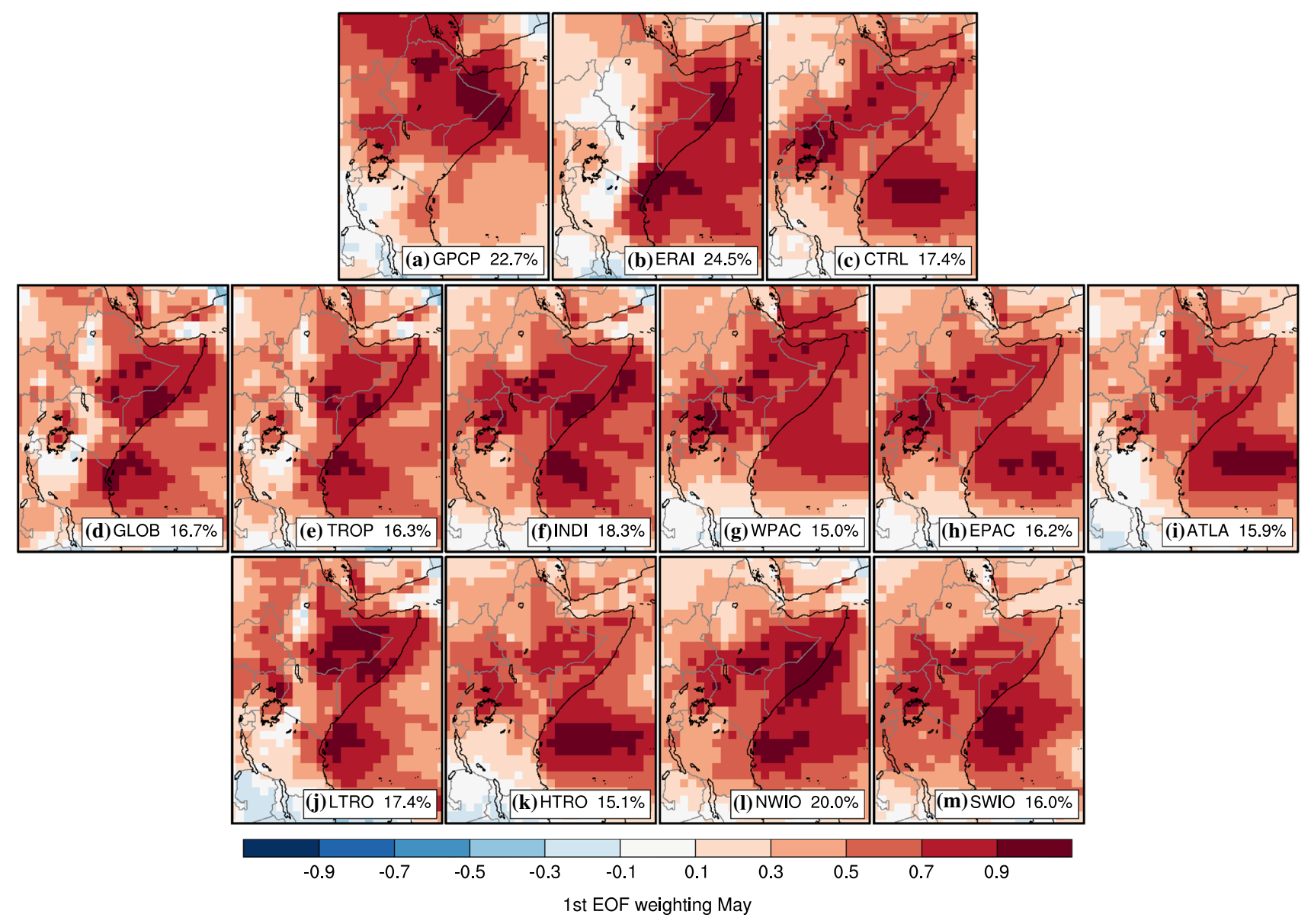

Fig. 5 Impact of experiments on the first EOF of May precipitation. a, b Show EOFs calculated from GPCP and ERA-Interim, whilst $\mathbf{c}-\mathbf{m}$ show this for the control and all experiments

Victoria. This region also has a large wet bias, suggesting that factors causing this large biases are not necessarily limiting local seasonal forecast skill.

The impact of the relaxation experiments on the ensemble mean correlation can be seen in Fig. 6b-k. These show the level of accuracy of the seasonal forecast which would be achieved if the time-varying forcing from the specified regions was perfect. Note that this assumes the daily ERAInterim sub-daily relaxation data is perfect (very likely not the case), and that assumes exact knowledge of the evolution of individual mesoscale systems, months in advance (very likely impossible). However the comparison of different experiments offers some idea of the relative contribution of the regions to potential forecast skill, as well as providing an upper bound estimate on seasonal forecast skill in this season. N.B. The correlation of ERA-Interim precipitation itself with precipitation observations could in theory provide an alternative estimate of the 'best-possible' precipitation simulation, since it assimilates all possible observations. This analysis is described as part of the following subsection, whilst here we focus purely on the correlation of relaxation reforecasts against observations.

The GLOB, TROP, INDI and LTRO experiments show the largest increases in correlation (Fig. 6b, c, d, h), with correlations over Kenya reaching over 0.8 . This identifies the Indian Ocean lower troposphere as a strong contributor to interannual variability. The Atlantic sector (Fig. 6g) also provides some increase in correlation; this may be as the relaxation essentially provides a perfect source of MJO propagation into the region, which has been shown to be a key contributor to seasonal total rainfall (Vellinga and Milton 2018).

The Pacific regions (Fig. 6e, f) show a minor impact, particularly the East Pacific. Analysis of individual months reveals that this improvement overwhelmingly occurs in March (Supplementary Fig. 3). This is consistent with results from (Camberlin and Philippon 2002), who hypothesise that cool SST in the eastern Niño 1.2 region is linked to above average Kenya/Uganda rainfall through low surface pressure in the northern Indian Ocean and a northward shift in the inter-tropical convergence zone. Analysis of individual 


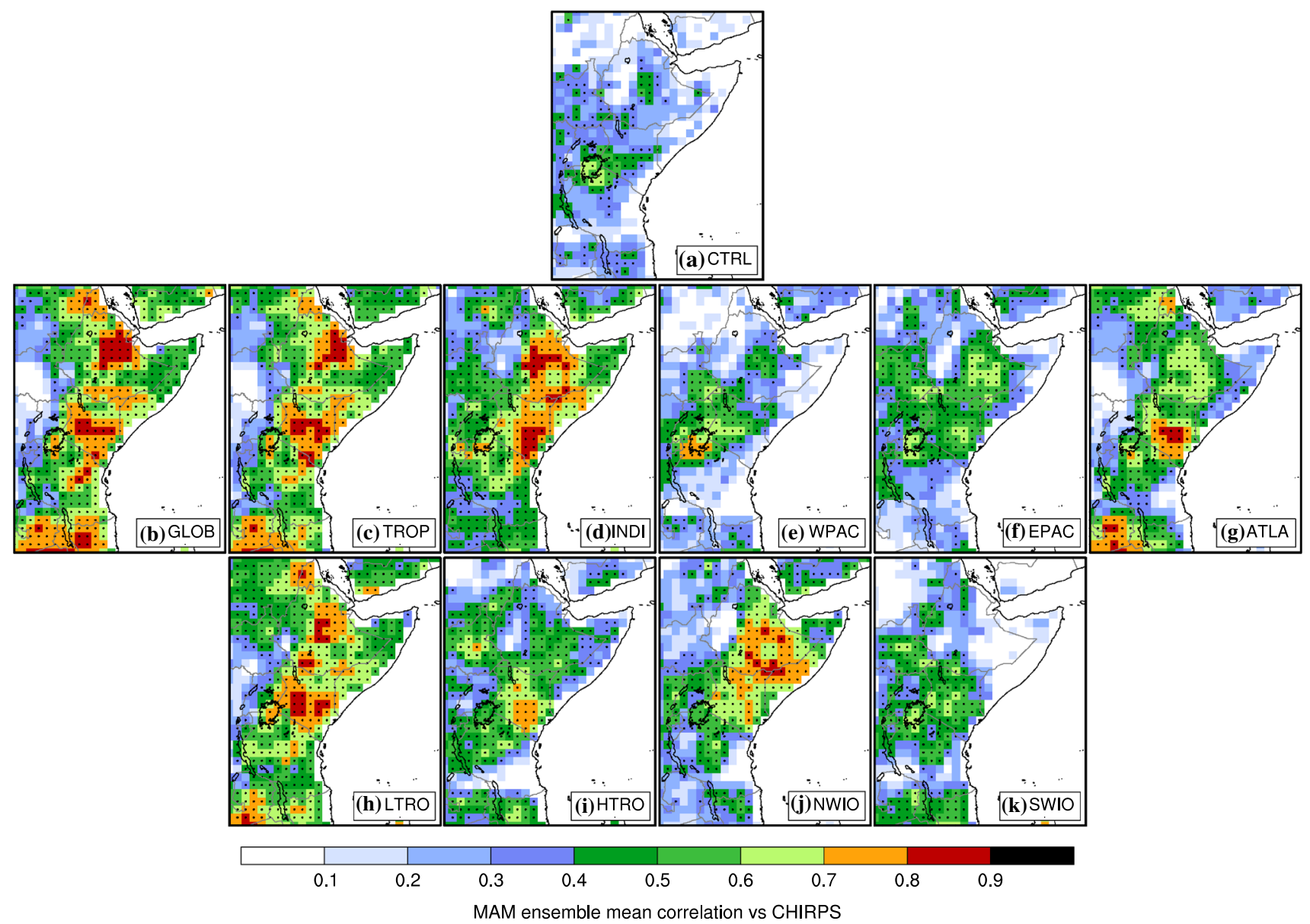

Fig. 6 Impact of experiments on ensemble mean correlation for total March-May precipitation, calculated 1981-2014 with respect to CHIRPS. Control (unrelaxed) correlation shown in a, correlation

months also indicates that correlations for April (supplementary Fig. 4) are lower in the control and all experiments compared to March and May, consistent with previous work identifying April as a month dominated by internal chaotic variations (Camberlin and Philippon 2002). The Northwest Indian Ocean provides a much greater increase in correlation compared to the Southwest, whilst the lower tropics relaxation provides a much greater increase than the upper tropics, which have a mild impact.

A summary of the impact of these experiments across all months is provided in Fig. 7. In each panel a series of related experiments are compared, indicating which experiment (if any) gives the highest improvement in correlation over the control. In the top panel the four tropical regions (INDI, WPAC, EPAC and ATLA) are compared, showing the Indian Ocean as the key driver across all months over the Horn of Africa, with its influence strongest in May and weakening into April. The Atlantic sector shows most impact for western Kenya and northern Tanzania in March, western Kenya in April and a large part of the southern region in May. In in all experiments in b-k. Stippling indicates correlations which are above a $95 \%$ significance level according to a t-test

addition southern parts of the domain are influenced strongly by the Atlantic, particularly in May.

The middle row of Fig. 7 shows the comparison between the NWIO and SWIO regions, testing the VW18 result. The Northwest Indian Ocean shows a clear influence over the Horn of Africa region in March and April and a reduced influence in May, whilst the Southwest region has some influence over northern Tanzania and southwest Kenya. The bottom row of Fig. 7 shows the comparison between the lower and upper tropical relaxation experiments, indicating that the lower troposphere has the dominant influence over interannual variability during the long rains. Sensitivity of these results to observational uncertainty is tested by recalculating correlations against GPCP and results are unchanged (Supplementary Fig. 6).

These results indicate the broad pattern of the influence of remote regions on the ensemble mean of seasonal forecasts. In order to make this impact more explicit, the forecasts for the long rains failure of 2011 are shown in Fig. 8 in each experiment. This event followed a failed short rains and 

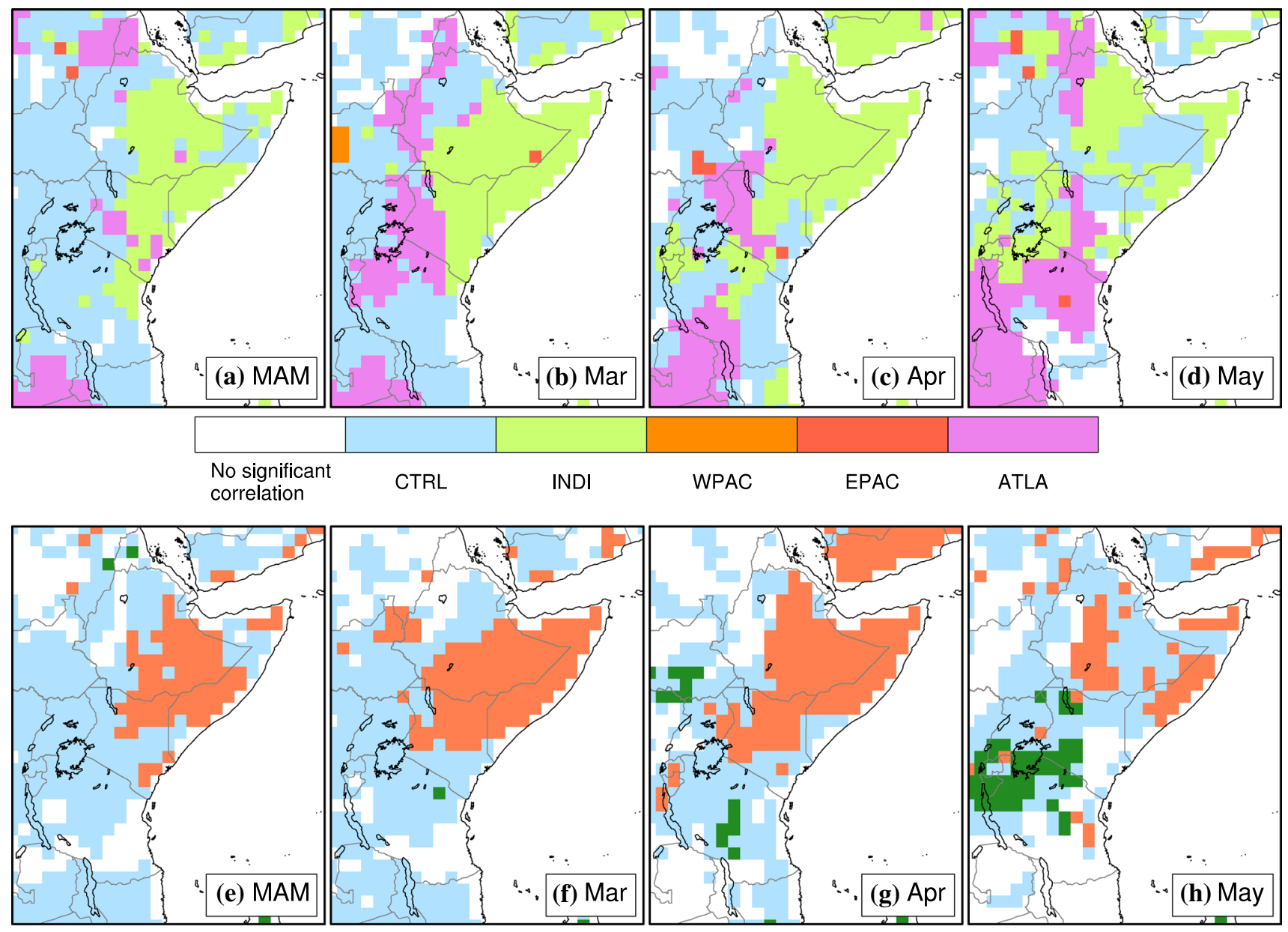

No significant

correlation

CTRL

NWIO

SWIO

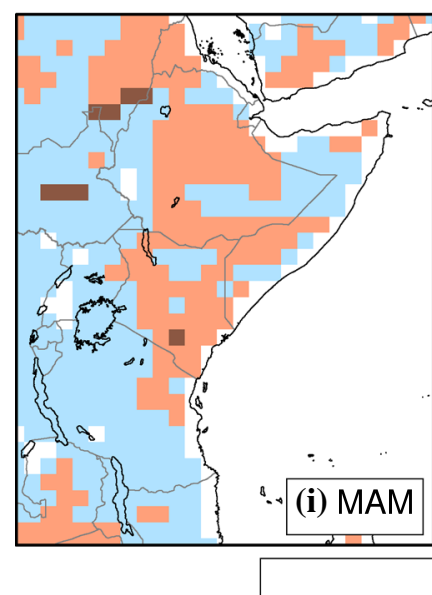

No significant correlation

Fig. 7 Comparing the impact of relaxation experiments on ensemble mean correlation for MAM, March, April and May (left to right panels). The colours indicate the experiment which provides the largest correlation (compared to CHIRPS), as long as it is larger than the control at a 95\% significance level (according to a $t$ test). CTRL colour is used where no experiment is has a correlation which is sig-

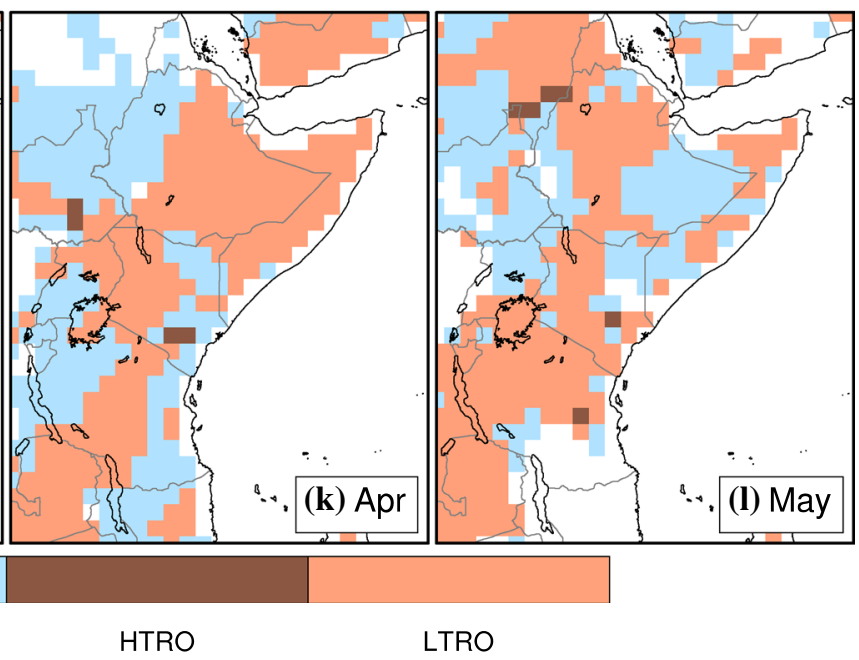

nificantly higher than the control, whilst no colour indicates that the experiment with the highest correlation is not significant. The top row compares the four regions INDI, WPAC, EPAC and ATLA. The middle row compares NWIO and SWIO in the same way and the bottom row compares HTRO and LTRO 


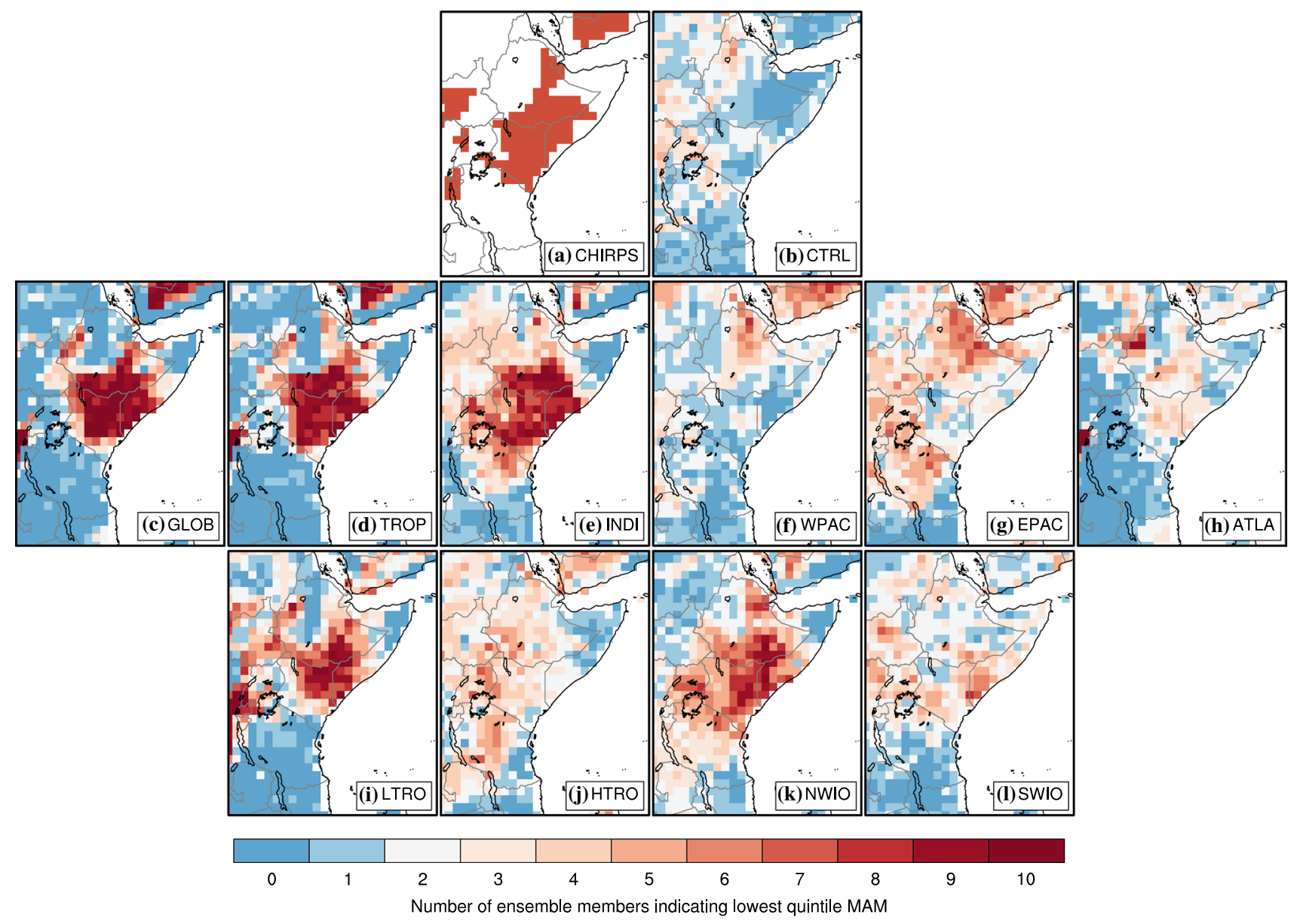

Fig. 8 Impact of experiments on simulation of 2011 long rains drought. a Indicates regions where CHIRPS March-May 2011 was below the 20th percentile. b Shows the control probability for a season below the 20th percentile, whilst b-l show this probability for

led to one of the largest humanitarian emergencies in the region in recent memory (OCHA 2011). Figure 8a shows the regions which experienced a one in five year rainfall deficit and Fig. 8b indicates that few control forecast ensemble members captured this event [consistent with analysis of the operational ECMWF seasonal forecast at the same lead time which showed little skill (Dutra et al. 2013)]. Figure 8c-1 show the number of members indicating a dry event in each of the relaxation experiment forecasts. Results are consistent with the analysis of ensemble mean correlation across the hindcast presented in Fig. 7. With the NWIO relaxation (Fig. 8k) almost every member is pushed toward dry conditions over the precise region experiencing a dry season over East Africa, indicating that processes in the Northwest Indian Ocean were strongly connected to this drought.

The significant improvement in model biases and forecast skill provided by relaxing the NWIO region demonstrates the importance of this region to long rains rainfall over East Africa. It also appears to corroborate one result from VM18, each of the experiments. Note that the color scale reflects the fact that one would expect two members to indicate a 20th percentile event on average, a number below or above two then represents a reduction or increase in the chance of a 20 th percentile event compared to normal

where a link is found between SST in this region and rainfall over East Africa. The mechanism proposed in VM18 is through direct heating of the boundary layer: warm SST anomalies heat the overlying atmosphere, leading to ascent and a reduction of the climatological subsidence cap over East Africa. To explore this further, extra relaxation experiments were run based on NWIO (full details in Table 2). Firstly, repeating the experiment but with the relaxation box limited to levels below $700 \mathrm{mb}$ diagnoses the importance of the lower troposphere in the region relative to the rest of the atmospheric column (NWLO). Subsequently experiments based on NWLO are carried out with only single parameters (dynamics, temperature surface pressure and moisture), relaxed alone in each separate experiment.

Results are shown in Fig. 9 for all forecast months separately. To show improvement over the control, the correlation is shown as a percentage scaled between the control and GLOB correlations. That is, a score of $0 \%$ indicates no improvement over the control, whilst $100 \%$ indicates that the 


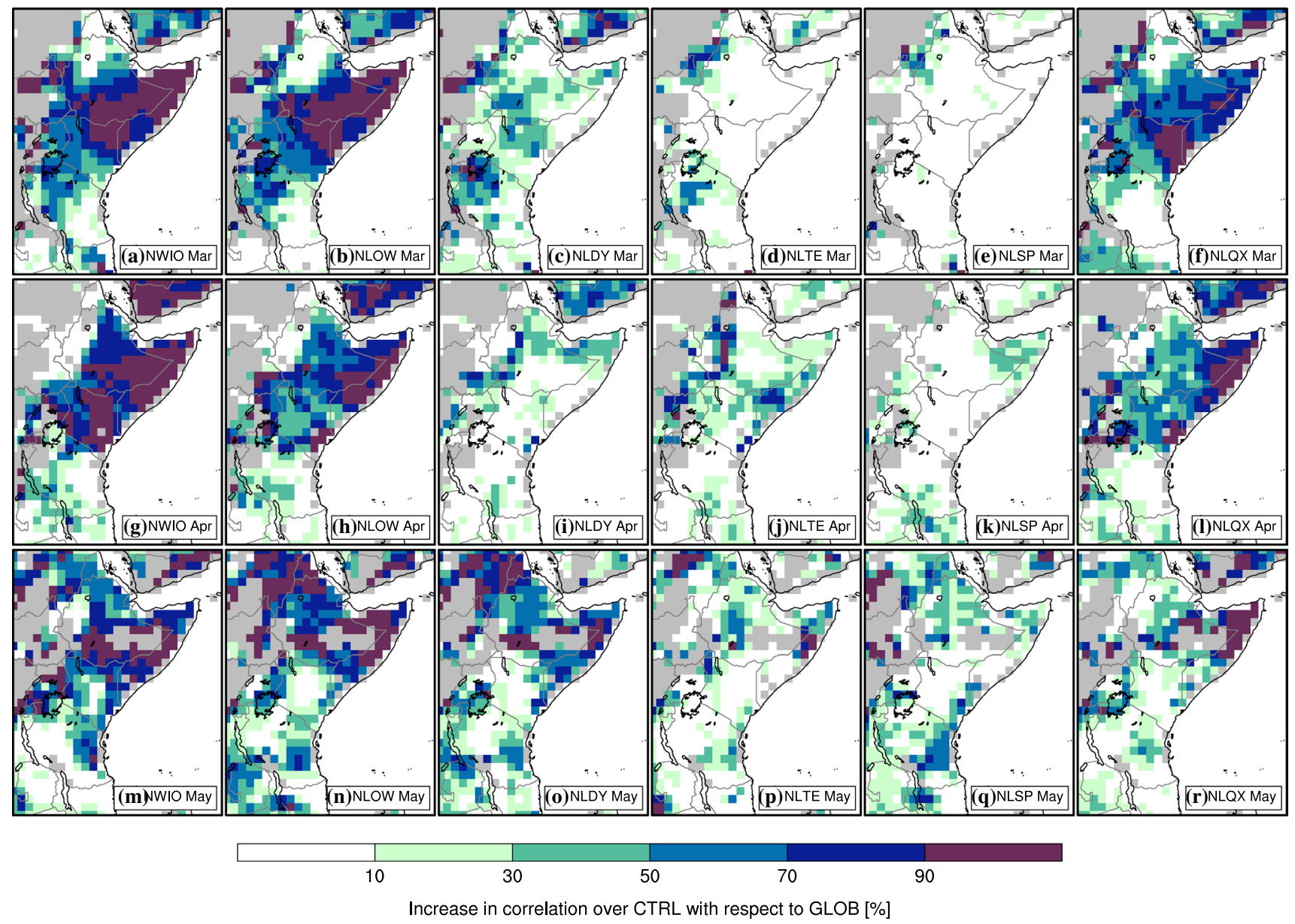

Fig. 9 Diagnosing the contribution of relaxation variables over the NWIO region, for months March, April and May (top to bottom row). Left to right panels show the improvement in correlation over CTRL for each experiment in Table 2, plotted as a percentage increase in correlation coefficient scaled between the correlation of CTRL and GLOB. A value of $0 \%$ indicates that the experiment gives

GLOB correlation can be reproduced from that experiment alone. To isolate regions where improvement is large, the regions where the $\mathrm{Z}$ test statistic of the difference of GLOB and control correlations is below 1 have been masked. For reference the unscaled correlations are shown in Supplementary Fig. 7.

Figure $9 \mathrm{a}, \mathrm{g}, \mathrm{m}$ indicate that in the northern part of the domain over $90 \%$ of the improvement from GLOB can be achieved by relaxing NWIO alone, for all three months. For March this result is unchanged when only levels below $700 \mathrm{mb}$ are relaxed, confirming the importance of nearsurface processes. Relaxing humidity fields alone in this lower troposphere reproduces a large amount of the correlation, particularly for the semi-arid lands of Kenya (Fig. 9f). By contrast, relaxation of temperature or surface pressure (Fig. 9d, e) alone is unable to improve the correlation, whilst no improvement over CTRL and $100 \%$ indicates the improvement is equal to the improvement found in the GLOB experiment. Regions have been masked where the improvement in correlation between GLOB and CTRL measured by a t-test is below a $\mathrm{z}$ score of 1 . For reference, corresponding maps of ensemble mean correlation are provided in supplementary Fig. 7

dynamics alone reproduces between $30-50 \%$ of the correlation improvement.

During April, NWIO reproduces the majority of the GLOB improvement, but in this month less of the improvement is reproduced when relaxation is limited to levels below $700 \mathrm{mb}$ (Fig. 9g, h). As in March, humidity alone is able to reproduce a large fraction of the correlation over the Horn of Africa (over 90\%), and to a lesser extent across Kenya and Ethiopia (around 50\%). Temperature relaxation alone has more of an impact in April compared to than March, with a fractional increase over the control of 10-30\% over most of the region, and up to $70 \%$ over the southern part of Somalia and western Ethiopia (Fig. 9j).

Results for May indicate a different relationship between East Africa and the Northwest Indian Ocean compared to March and April. Whilst most of the GLOB correlation is reproduced by NWIO below $700 \mathrm{mb}$ alone, 

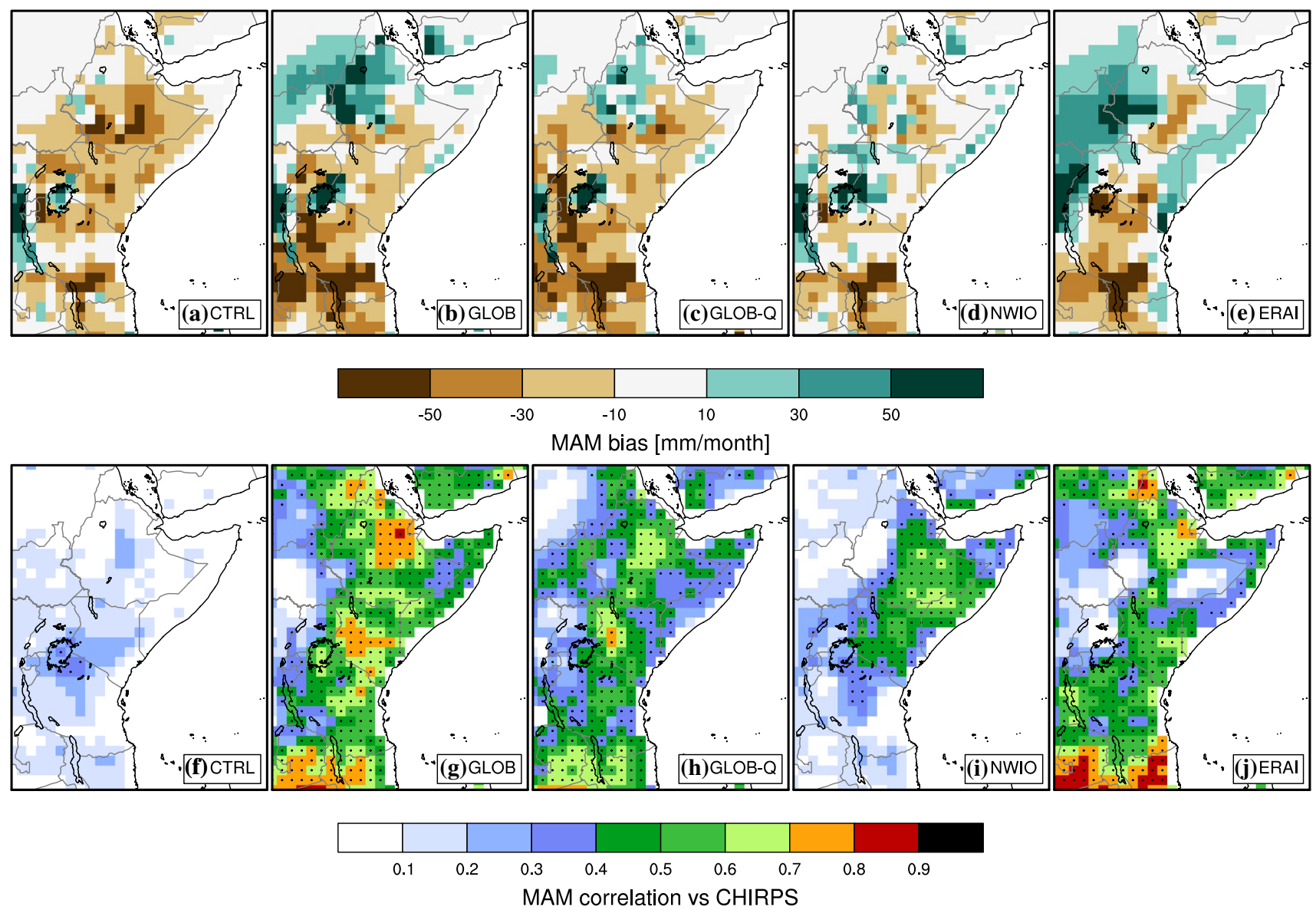

Fig. 10 Comparative analysis to determine impact of ERA-Interim humidity relaxation on MAM precipitation. Mean precipitation bias (a-e) and correlation with CHIRPS across all years $(\mathbf{f}-\mathbf{i})$. Left to right shows control, GLOB relaxation, GLOB-Q as GLOB without humidity, NWIO. Rightmost column shows the bias of ERA-Interim precipitation against CHIRPS (e) and the correlation of ERA-Interim against CHIRPS (j). Note that correlations in $(\mathbf{f}-\mathbf{i})$ are not ensemble

relaxation of the dynamical fields alone now gives the biggest improvement over the control; reproducing over $50 \%$ of the GLOB improvement over most of Ethiopia and Somalia, and over $90 \%$ in places (Fig. 9o). Humidity still has an impact, particularly over the tip of Somalia where over $90 \%$ of the GLOB correlation is reproduced, but is less influential than dynamics across the rest of the region. This is consistent with the idea that the end of the long rains (and therefore May precipitation) is controlled by the strengthening of the Somali Jet in advance of the Indian Monsoon, a dynamical phenomenon leading to enhanced divergence and wind shear that limits convection (Camberlin et al. 2010). Notably over the tip of Somalia large improvements over the control can be achieved by relaxing most variables individually, suggesting that at this time interannual variability in dynamics, humidity and temperature at this time is tightly coupled. mean correlations, but rather have been calculated for each member separately and averaged, as a fair test against the single-member ERA-Interim. Stippling in (f-i) indicates where $50 \%$ of ensemble members are significant at a test $95 \%$ level, and in (j) indicates where values are above the $95 \%$ significance level according to a t-test

\subsection{Diagnosis of errors in humidity relaxation fields}

Previous analysis has shown that all the experiments which include relaxation on the western boundary show a wet bias (Fig. 2). It has speculated that this bias is related to errors in ERA-Interim humidity over the region to the west of East Africa. In addition, Fig. 6 indicates a significant reduction of correlation from the control in over Uganda in the same experiments, suggesting the ERA-Interim relaxation fields over central Africa as a source of the error. To explore this hypothesis, an additional experiment has been carried out for the GLOB region but with relaxation of humidity fields turned off (GLOB-Q).

The impact on bias and correlations of this GLOBQ experiment is shown in Fig. 10. Results for relevant experiments are also shown for comparison (control, GLOB and NWIO) and in addition the bias and correlation 
of ERA-Interim reanalysis itself against CHIRPS is also shown. In order to make a fair comparison with the ERAInterim correlation, the correlations here are calculated for each ensemble member separately across all years and averaged across all members (rather than showing again ensemble mean correlations, which implicitly increase the signal to noise ratio).

By turning off relaxation of humidity the wet bias over the northern part of the region is reduced (Fig. 10b, c). However, turning off the humidity also reduces the correlation over most of the region (Fig. 10g, h). ERA-Interim humidity fields west of the domain therefore have a negative impact on the precipitation bias over East Africa whilst contributing positively to the correlation. In addition, switching off the humidity fields does not fix the reduction of correlation over Uganda, suggesting further errors in ERA-Interim to the west (e.g. in dynamics and temperature).

It is interesting to evaluate ERA-Interim precipitation here in the same way as the other model outputs. A comparison to CHIRPS reveals a large wet bias over much of East Africa, over the northwest as well as the coastal region (Fig. 10e). Given that reanalysis takes advantage of available observations to constrain a model simulation, it is surprising that this bias is larger than the unrelaxed control experiment; one might expect that a model taking advantage of partial observations of system reproduces the full state compared to the same model without access to those observations. Furthermore for the northeast region the correlation of the NWIO experiment (Fig. 10i) actually provides a better correlation with the observations than ERA-Interim does (Fig. 10j).

One explanation for this surprising finding is that the assimilation of observations are somehow having a negative effect on precipitation processes over the region. For example if the model has significant errors in the placement of climatological features [e.g. the Turkana jet (Nicholson 2017)], then continually pushing the model away from its own climate through data assimilation may disrupt its ability to represent forced variability around its own mean state. Another likely factor may be that the older model version used to produce ERA-Interim. Although ERA-Interim uses the same resolution as these experiments (T255), the cycle used in the production of the reanalysis was released in 2006 (Cy31r1), compared to the cycle used for these experiments released in 2015 (Cy41r1). Significant improvements to the model have occurred during that time which may partially or fully explain this result. The implication of this is that any future work involving relaxation experiments (particularly over East Africa) should make use of the upcoming ERAInterim replacement, ERA5, for which analysis of initial data has demonstrated improvements in humidity biases over Africa (ECMWF 2019).

\section{Discussion}

The relaxation experiments presented here have examined model simulation of the East Africa long rains and its sensitivity to forcing from remote regions. Overall the results support the VM18 finding that processes in the Northwest Indian Ocean are a key influence on long rains rainfall, particularly in March and April. Single-variable relaxation in this region points to humidity as playing a key role: relaxing this variable alone is able to reproduce the majority of the improvement seen with a full global relaxation. In comparison relaxing temperature or dynamical fields alone does not produce nearly the same level of improvement in forecasts. It may be the case that interannual variations in humidity over the Northwest Indian Ocean are actually a key driver of interannual variability of the long rains (not temperature or dynamics, as the proposed VM18 mechanism of ascent driven by boundary-layer heating would suggest). However perhaps a more likely hypothesis is that biases or errors in humidity fields are hampering a realistic simulation of the VM18 mechanism in the model (e.g. a dry bias causing inadequate coupling between the boundary layer and vertical motion). By relaxing humidity fields toward reanalysis any such bias would be corrected, allowing realistic operation of other mechanisms. Future work should focus on the exact nature and timescales of the processes occurring over the Northwest Indian Ocean, particularly the role of humidity and the impact of model errors in correctly simulating boundary-layer processes. Consistent with VM18, this region in general is shown to be key for reproducing the correct spatial structure of anomalies, the mean bias and interannual variability. In addition relaxation of the region provides a strong improvement to the forecasts of the high-impact 2011 long rains failure: consistent with previous work showing that the 2011 dry conditions can be explained by cold SST in the Northwest Indian Ocean, as well as weak MJO activity and a westerly Quasi-Biennial Oscillation.

Model errors over the Northeast Indian Ocean may also be linked to previous work on the seasonal predictability of onset and cessation over East Africa (MacLeod 2018). In observations long rains cessation over the northeastern tip and coast of East Africa is found to have a strong negative correlation with central African zonal winds and a positive correlation inland. In contrast the ECMWF seasonal prediction system is unable to represent this strong spatial gradient in the relationship and instead shows a positive correlation across the entire region. Given the proximity to the Northwest Indian Ocean region these errors may be related. Processes over this region are therefore a key priority for further study, both in terms of analysis of observations and in multi-model forecast assessment. 
Results indicate that the ECMWF seasonal model has a dry bias and produces anomalies with a spatial pattern which is too loosely constrained to the coast. EOF patterns tend to 'leak' out over the ocean, with insufficient power over the continent. In the short term it may be possible to fix these biases in post-processed model output, either by providing the forecast in terms of anomalies relative to its own climate, or through a more sophisticated EOF-based Canonical Correlation Analysis approach such as that used in the Climate Predictability Tool of IRI (Mason and Tippett 2018). However in the long term it is desirable to fix such unrealistic model behaviour at source, as these errors may have knock-on effects to other regions and variables. Relaxation experiments which include the Northwest Indian Ocean region offer improvements in this spatial structure, which suggests a source of these errors in spatial structure of anomalies. In addition the control EOF pattern in May seems to be quite similar to the observed EOF pattern in April, raising the possibility of model error in the timing of processes related to the seasonal cycle.

Although relaxation experiments are able to improve the spatial patterns of anomalies the variance of the first EOF in the control is too low and is unaffected by any relaxation experiment. This suggests that local processes make some contribution to interannual variability and that there are model errors in their representation and links to large-scale factors. A likely candidate for such variability is variability in the low-level Turkana Jet (Kinuthia 1992), which has been shown to be associated with regional aridity (Nicholson 2016). The characteristics of the jet are strongly affected by $10 \mathrm{~km}$-scale landmasses within the Turkana channel, which suggests that the $80 \mathrm{~km}$ horizontal resolution of these simulations is unable to properly represent jet structure and variability. This may contribute toward the lack of power in the first EOF over the region and an investigation into the representation of the Turkana jet in model simulations would be help to confirm this hypothesis. In addition a persistent wet bias over Lake Victoria and dry bias near Lake Malawi are insensitive to any remote relaxation, suggesting model errors in the representation of coupled atmosphere-lake processes which may also play a role in amplifying larger-scale variability.

One caveat to the relaxation experiments is the assumption that the relaxation field (in this case, ERA-Interim) represents reality. Where the climate system is poorly-observed, this assumption is clearly strained. Indeed, results presented here show that by relaxing humidity over central Africa a large wet bias is introduced into East Africa, highlighting errors in the ERA-Interim estimation of humidity.

Finally, relaxation experiments in the Pacific regions do not offer significant improvements to the simulations, although the East Pacific seems to have an influence in March. This is consistent with observational analysis suggesting a connection between a cool eastern Pacific and enhanced Kenya rainfall (Camberlin and Philippon 2002) and further work is needed to explore this link. Improved understanding of prediction skill of such sub-seasonal monthly averages (alongside improvement in understanding and representation of processes discussed above) then offers a route to improved predictability in the long rains season, which ultimately may lead to useful early warnings for a region that remains at serious risk from climate variability.

Acknowledgements I would like to thank colleagues at ECMWF and the UK Met Office for useful discussions of results, in particular Michael Vellinga, as well another anonymous reviewer. Thanks to ECMWF for the provision of computing resources; all experimental data is available at the ECMWF archive, details of access are available on request. CHIRPS data was provided by the Climate Hazards Group of UC Santa Barbara, whilst GPCP data was provided by the NOAA/ OAR/ESRL PSD, Boulder.

Funding This work was supported by the NERC/DfID project ForPAc: Toward Forecast-based Preparedness Action (NE/P000673/1).

Open Access This article is distributed under the terms of the Creative Commons Attribution 4.0 International License (http://creativeco mmons.org/licenses/by/4.0/), which permits unrestricted use, distribution, and reproduction in any medium, provided you give appropriate credit to the original author(s) and the source, provide a link to the Creative Commons license, and indicate if changes were made.

\section{References}

Adler RF, Huffman GJ, Chang A, Ferraro R, Xie PP, Janowiak J, Rudolf B, Schneider U, Curtis S, Bolvin D et al (2003) The version-2 global precipitation climatology project (gpcp) monthly precipitation analysis (1979-present). J Hydrometeorol 4(6):1147-1167

Balmaseda MA, Mogensen K, Weaver AT (2013) Evaluation of the ECMWF ocean reanalysis system ORAS4. Q J R Meteorol Soc 139(674):1132-1161. https://doi.org/10.1002/qj.2063

Balsamo G, Salgado R, Dutra E, Boussetta S, Stockdale T, Potes M (2012) On the contribution of lakes in predicting near-surface temperature in a global weather forecasting model. Tellus A Dyn Meteorol Oceanogr 64(1):15,829. https://doi.org/10.3402/tellu sa.v64i0.15829

Batté L, Déqué M (2011) Seasonal predictions of precipitation over Africa using coupled ocean-atmosphere general circulation models: skill of the ENSEMBLES project multimodel ensemble forecasts. Tellus S A Dyn Meteorol Oceanogr 63(2):283-299. https ://doi.org/10.1111/j.1600-0870.2010.00493.x

Camberlin P, Fontaine B, Louvet S, Oettli P, Valimba P (2010) Climate adjustments over africa accompanying the indian monsoon onset. J Clim 23(8):2047-2064

Camberlin P, Philippon N (2002) The east african march-may rainy season: associated atmospheric dynamics and predictability over the 1968-97 period. J Clim 15(9):1002-1019

Dee DP, Uppala SM, Simmons AJ, Berrisford P, Poli P, Kobayashi S, Andrae U, Balmaseda MA, Balsamo G, Bauer P, Bechtold P, Beljaars ACM, van de Berg L, Bidlot J, Bormann N, Delsol C, Dragani R, Fuentes M, Geer AJ, Haimberger L, Healy SB, Hersbach H, Hólm EV, Isaksen L, Kållberg P, Köhler M, Matricardi M, McNally AP, Monge-Sanz BM, Morcrette JJ, Park BK, Peubey 
C, de Rosnay P, Tavolato C, Thépaut JN, Vitart F (2011) The ERA-interim reanalysis: configuration and performance of the data assimilation system. Q J R Meteorol Soc 137(656):553-597. https://doi.org/10.1002/qj.828

Dutra E, Magnusson L, Wetterhall F, Cloke HL, Balsamo G, Boussetta S, Pappenberger F (2013) The 2010-2011 drought in the Horn of Africa in ECMWF reanalysis and seasonal forecast products. Int J Climatol 33(7):1720-1729. https://doi.org/10.1002/joc.3545

ECMWF (2019) quality of era-interim and comparison with other datasets: relative humidity. https://perma.cc/39UC-XAPZ. Accessed 10 June 2019

Funk C, Peterson P, Landsfeld M, Pedreros D, Verdin J, Shukla S, Husak G, Rowland J, Harrison L, Hoell A et al (2015) The climate hazards infrared precipitation with stations a new environmental record for monitoring extremes. Sci Data 2:150,066

GHACOF (2018) Statement from the forty eighth Greater Horn of Africa Climate Outlook Forum (GHACOF 48) for March to May 2018. https://perma.cc/Q3HF-YVC2. Accessed 10 June 2019

Govt. Kenya (2018) The 2018 long rains season assessment report. https://perma.cc/5EJM-4FKD

Hastenrath S, Nicklis A, Greischar L (1993) Atmospheric-hydrospheric mechanisms of climate anomalies in the western equatorial Indian Ocean. J Geophys Res 98(C11):20,219. https://doi. org/10.1029/93JC02330

Jung T, Palmer TN, Rodwell MJ, Serrar S (2010) Understanding the anomalously cold European winter of 2005/06 using relaxation experiments. Mon Weather Rev 138(8):3157-3174. https://doi. org/10.1175/2010MWR3258.1

Kilavi M, MacLeod D, Ambani M, Robbins J, Dankers R, Graham R, Helen T, Salih AAM, Todd MC (2018) Extreme rainfall and flooding over central Kenya including Nairobi city during the long-rains season 2018: causes, predictability, and potential for early warning and actions. Atmosphere 9(12):472

Kinuthia JH (1992) Horizontal and vertical structure of the lake turkana jet. J Appl Meteorol 31(11):1248-1274

Leutbecher M, Lock SJ, Ollinaho P, Lang ST, Balsamo G, Bechtold P, Bonavita M, Christensen HM, Diamantakis M, Dutra E, English S, Fisher M, Forbes RM, Goddard J, Haiden T, Hogan RJ, Juricke S, Lawrence H, MacLeod D, Magnusson L, Malardel S, Massart S, Sandu I, Smolarkiewicz PK, Subramanian A, Vitart F, Wedi N, Weisheimer A (2017) Stochastic representations of model uncertainties at ECMWF: state of the art and future vision. Q J R Meteorol Soc 143(707):2315-2339. https://doi.org/10.1002/qj.3094

MacLeod D (2018) Seasonal predictability of onset and cessation of the East African rains. Weather Clim Extremes 21:27-35

MacLeod D (2019) Seasonal forecast skill over the Greater Horn of Africa: a verification atlas of System 4 and SEAS5. Part 1:
Precipitation. Available at https://www.ecmwf.int/node/18906. Accessed 10 June 2019

Mason SJ, Tippet MK (2019) Climate Predictability Tool version 15.7.10. https://doi.org/10.7916/d8-teh5-k226, available at https ://academiccommons.columbia.edu/doi/10.7916/d8-teh5-k226. Accessed 10 June 2019

Mutai CC, Ward MN (2000) East African rainfalland the tropical circulation/convection on intraseasonal tointerannual timescales. J Clim 13(22):3915-3939. https://doi.org/10.1175/15200442(2000)013<3915:EARATT>2.0.CO;2

Mwangi E, Wetterhall F, Dutra E, Di Giuseppe F, Pappenberger F (2014) Forecasting droughts in East Africa. Hydrol Earth Syst Sci 18(2):611-620. https://doi.org/10.5194/hess-18-611-2014

Nicholson S (2016) The turkana low-level jet: mean climatology and association with regional aridity. Int J Climatol 36(6):2598-2614

Nicholson SE (2014) The predictability of rainfall over the Greater Horn of Africa. Part I: prediction of seasonal rainfall. J Hydrometeorol 15(3):1011-1027. https://doi.org/10.1175/JHM-D-13-062.1

Nicholson SE (2017) Climate and climatic variability of rainfall over eastern Africa. Rev Geophys 55(3):590-635. https://doi. org/10.1002/2016RG000544

OCHA (2011) United Nations Office for the Coordination of Humanitarian Affairs: Drought Crisis Interim Situation Report 4 August 2011. https://perma.cc/TGC8-2RSR. Accessed 10 June 2019

OCHA (2018) United Nations Office for the Coordination of Humanitarian Affairs: regional outlook for the Horn of Africa and Great Lakes April-June 2017. https://perma.cc/33K5-EJA3. Accessed 10 June 2019

Ogallo LJ, Janowiak JE, Halpert MS (1988) Teleconnection between seasonal rainfall over East Africa and global sea surface temperature anomalies. J Meteorol Soc Jpn 66(6):807-821. https://doi. org/10.2151/jmsj1965.66.6_807

Song Y, Semazzi FH, Xie L, Ogallo LJ (2004) A coupled regional climate model for the lake victoria basin of east africa. Int J Climatol 24(1):57-75

Vellinga M, Milton SF (2018) Drivers of interannual variability of the East African long rains. Q J R Meteorol Soc 144(712):861-876. https://doi.org/10.1002/qj.3263

Watson PA, Weisheimer A, Knight JR, Palmer T (2016) The role of the tropical west pacific in the extreme northern hemisphere winter of 2013/2014. J Geophys1 Res Atmos 121(4):1698-1714

Publisher's Note Springer Nature remains neutral with regard to jurisdictional claims in published maps and institutional affiliations. 